\title{
Uma Discussão Teórica sobre a Importância da Gestão do Conhecimento na Administração Pública \\ Flávia Souza Bezerra ${ }^{1}$; Ricardo dos Santos Souza ${ }^{2}$; Fernanda Roda de Souza Araújo. Cassundé
}

\begin{abstract}
Resumo: Na sociedade contemporânea, a gestão pró-ativa dos recursos de conhecimento passou a ser condição sine qua non para a sobrevivência de qualquer entidade. $\mathrm{O}$ foco fundamental não é mais o armazenamento e o acesso à informação, mas sim, uma gestão voltada para o conhecimento que reflita na qualidade e resultados dos serviços prestados pela organização. Este trabalho tem como objetivos: discutir questões pertinentes a Gestão do Conhecimento, bem como, averiguar se essa gestão pode contribuir para a geração de resultados positivos na Administração Pública que resulte em benéficios para o cidadão. Conclui-se que a gestão de conhecimento é de suma importância para o desenvolvimento de qualquer empresa, e no que se refere ao nosso objeto de estudo, a administração pública, sua importância se potencializa em decorrência da abrangência que tais instituições possuem para o desenvolvimento de um país; sendo muitas vezes, importante fonte de desenvolvimento interno. Neste sentido, a gestão do conhecimento enriquece a capacidade da administração pública. Todavia, para que tal intento possa ser alcançado, ações precisam ser feitas, onde se deve investir no desenvolvimento e no compartilhamento do conhecimento, seja ele intrínseco ou extrínseco, de tal modo que tal ação torne esse conhecimento fluido, dinâmico, e em movimento.
\end{abstract}

Palavras-chave: Gestão do Conhecimento. Resultados. Administração Pública.

\section{A Discussion on Theoretical Knowledge Management Importance of Public Administration}

\begin{abstract}
In contemporary society, the proactive management of knowledge resources has become a sine qua non for the survival of any organization. The key focus is no longer the storage and access to information, but rather a management focused on knowledge that reflects the quality and results of the services provided by the organization. This study aims: to know through literature matters pertaining to knowledge management, as well as determine whether this management can contribute to the generation of positive results in the public administration that results in benefits for the citizens. The methodology used in this study was Literature Review grounded in books and publications indexed to SciELO - Scientific Electronic Library Online, among others. It is concluded that knowledge management is of paramount importance for the development of any company, and with regard to our object of study, public administration, its importance is enhanced due to the extent that such institutions have to develop A country; It is often an important source of internal development. In this sense, knowledge management enriches the capacity of public administration. However, for this purpose can be achieved, actions need to be done, where you should invest in the development and sharing of knowledge, be it intrinsic or extrinsic, so that such action makes this knowledge fluid, dynamic, and moving.
\end{abstract}

Keywords: Knowledge Management. Results. Public administration.

\footnotetext{
${ }^{1}$ Pós-graduanda em Gestão Pública da Universidade Federal do Vale do São Francisco. Graduada em Pedagogia Gestão e Docência dos Processos Educativos pela Universidade do Estado da Bahia. E-mail: fllaviabz@ gmail.com

${ }^{2}$ Pós- graduando em Gestão Pública da Universidade Federal do Vale do São Francisco. Graduado em Direito pela Universidade do estado da Bahia. E-mail: ricardodel@bol.com.br

${ }^{3}$ Doutora em Administração pela Universidade Federal de Pernambuco. Professora do Colegiado de Administração da Universidade Federal do Vale do São Francisco. Email: fernanda.roda@univasf.edu.br
} 


\section{Introdução}

O panorama mundial, sem sombra de dúvidas, passou por grandes transformações nas últimas décadas. Essas alterações fizeram com que as empresas necessitassem adaptar seu modo de atuação, com o intuito de se manterem competitivas e maleáveis em face aos novos preceitos mercadológicos a serem seguidos. Somente com uma clara compreensão dessas novas exigências de mercado, uma empresa poderá tomar decisões e realizar ações adequadas e eficientes para seu crescimento. Destacando que um dos pontos cruciais para que a administração de uma determinada organização, seja ela pública ou privada, obtenha sucesso, é o conhecimento.

O Brasil, a exemplo de muitas outras nações, marcha na direção da economia da informação. A habilidade produtiva não é mais completamente dependente de capital e de equipamento. A informação e o conhecimento tornam-se cada vez mais relevantes. Logo, percebe-se o surgimento de novos desafios para o desenvolvimento do país. Na Era da Informação, o sucesso é consequência do planejamento, estratégia, captação de recursos e organização dos ativos da informação e do conhecimento de um grupo e do apoio às organizações para enfrentar um novo cenário de negócios. Neste sentido, a Gestão do Conhecimento pode oferecer os instrumentos necessários para auxiliar os atores sociais envolvidos no processo de desenvolvimento, a desempenhar atividades estratégicas (BATISTA, 2012).

Nesse novo cenário, em que o diferencial competitivo ao bom andamento das tarefas, é o conhecimento; a produção intelectual traz maior capacidade de resolução de rotinas físicas e intelectuais de maneira rápida e, por conseguinte, melhor geração de resultados. Assim, neste novo contexto, o termo Gestão do Conhecimento é mencionado pela primeira vez por Davenport e Prusak, no período em que a reengenharia acontecia fortemente nas empresas, determinando a perda de talentos organizacionais (REIS, 2007).

Peter Drucker (2001) diz que na sociedade contemporânea, o conhecimento se tornou o recurso básico para as pessoas e para a economia de modo geral, e que a terra, a mão-de-obra, o capital, que são os tradicionais fatores de produção, não desaparecem, todavia, tornaram-se secundários.

Neste diapasão, as questões pertinentes ao trabalho e às pessoas, assumiram vital relevância. Gestão de pessoas, competências, capacidades pessoais e organizacionais, capital intelectual, aprendizagem, criação e manutenção de valores, ética e responsabilidade social são assuntos que se transformaram em pontos cruciais para o processo administrativo, ocupando grande espaço nos debates e nas tomadas de decisões. Na busca de novos paradigmas de gestão, as organizações observam que os desafios impostos pelo ambiente externo, no que concerne às empresas e pelas novas condições no âmbito do trabalho, não podem mais ser sobrepujados pelo tradicional processo de 
gestão de pessoas, haja vista que está evidente que a gestão do conhecimento é condição sine qua non para a qualidade nos serviços e, consequentemente, para o bom andamento nos negócios.

Assim, numa tentativa de resumir o pensamento de diferentes pesquisadores, Reis (2007, p. 13), aponta que "a Gestão do Conhecimento seria um processo de identificação, pesquisa, compartilhamento, convergência e criação de conhecimentos úteis, oriundos de fontes internas e externas à organização, para que esta possa atingir os seus objetivos estratégicos".

Observa-se que o empenho de muitos autores em estudar acerca dessa temática tem crescido bastante nos últimos anos, de maneira que atualmente encontra-se um vasto campo de publicações a esse respeito, contudo, no âmbito público, a literatura ainda é escassa, por este motivo, pesquisar sobre a Gestão do Conhecimento na Administração Pública torna-se viável e essencial, justificando assim, a realização deste trabalho.

Assim, surgiu o seguinte questionamento: a Gestão do Conhecimento é geradora de resultados positivos na Administração Pública? Ademais, o presente estudo teve como objetivo: discutir, através da literatura, questões pertinentes a Gestão do Conhecimento, bem como, averiguar se essa gestão pode contribuir para a geração de resultados positivos na Administração Pública, resultando, pois, em benéficios para o cidadão.

\section{Discussão}

\section{Administração Pública: Conceitos}

De acordo com Daft (2010), administração é o alcance dos objetivos organizacionais de forma eficiente e eficaz através do planejamento, organização, liderança e controle dos recursos organizacionais. Essa definição abrange as quatro funções da Administração que são: planejar, organizar, dirigir e controlar, e o seu fim que é a realização de um trabalho com eficiência e eficácia.

Mello (2011, p. 153 apud Melo et al. 2013, p.1) sugere que:

a Administração Pública pode ser centralizada e descentralizada. A primeira situação ocorre quando a atividade administrativa "é exercida pelo próprio Estado, ou seja, pelo conjunto orgânico que lhe compõe a intimidade". Na segunda ocorrência a atividade gerencial é executada "por pessoa ou pessoas distintas do Estado". Ainda segundo o mesmo autor, descentralização e desconcentração são conceitos diferentes: a descentralização "pressupõe pessoas jurídicas diversas" enquanto que "a desconcentração está sempre referida a uma só pessoa, pois cogita-se da distribuição de competências na intimidade dela, mantendo-se, pois, o liame unificador da hierarquia. 
Para Nascimento (2010), a Administração Pública pode ser burocrática e gerencial. As duas são distintas, haja vista que a Administração Pública burocrática concentra-se no processo; é autorreferente; define os métodos para a contratação de recursos humanos; aquisição de bens e serviços; atende às demandas dos cidadãos; tem controle de procedimentos. Já a Administração Pública gerencial dirige-se para os resultados; é direcionada para o cidadão; combate o nepotismo e a corrupção; não aceita métodos rígidos; define os indicadores de desempenho; usa contratos de gestão. $\mathrm{O}$ autor supracitado concorda com a premissa de que a Administração Pública gerencial responde à busca de meios apropriados para enfrentamento da crise fiscal do Estado, como estratégia para diminuir custos e tornar mais competente a gestão dos serviços que competem ao Estado e como máquina de proteção ao patrimônio público.

Uma definição interessante foi proposta pelo Instrumento para Avaliação da Gestão Pública (2007, p. 54) quando diz que:

\begin{abstract}
entende-se administração pública como: (...) o conjunto de entidades que compõem o Estado, voltadas para a prestação de serviços públicos e o atendimento das necessidades do cidadão e da coletividade. É constituída da administração direta e da administração indireta, esta formada por autarquias, fundações, empresas públicas, sociedades de economia mista e organizações sociais. É subdividida em poderes (executivo, legislativo e judiciário) e em esferas (federal, estadual e municipal).
\end{abstract}

Coforme Cong; Pandya (2003 apud BATISTA, 2012), as organizações públicas têm como público-alvo partes interessadas, tais como: cidadãos, usuários, governos municipal e estadual, sindicatos, associações de classe, servidores públicos, grupos de pressão etc. Por isso, é necessário que para a Administração Pública um modelo de Gestão do Conhecimento que inclua as dimensões Cidadão-usuário e Sociedade, o que não se vê nos modelos construídos para organizações privadas. Essas dimensões são relevantes, visto que a Gestão do Conhecimento pode exercer um papel importante na administração pública ao ampliar a capacidade social e ao colaborar para que o cidadão e a sociedade civil participem de forma efetiva no processo de tomada de decisões das organizações públicas.

É válido ressaltar que este tipo de administração deve por fim à arbitrariedade burocrática, já que os direitos do cidadão e sua igualdade perante a administração devem ser respeitados. Para isso, é fundamental identificar quem são esses cidadãos, prestar-lhes contas e ajustar-se às suas reais necessidades (TISCOSKI, 2014). Seu direcionamento deve ter o objetivo de oferecer para o indivíduo serviços de qualidade e obtenção de resultados positivos; como estratégia, se deve fazer uso da descentralização e do incentivo à criatividade e inovação, envolver, ainda, uma modificação na estratégia de gestão, que precisa ser colocada em ação, nos moldes de uma estrutura administrativa 
reformada, cuja proeminência seja a descentralização e a delegação de autoridade, ou seja, características da nova administração pública.

O plano "mestre" da nova administração pública consiste em desenvolver nos funcionários um acordo voltado à construção de uma sociedade mais preparada para o enfrentamento das novas ações contextualizadas em uma era de transformações. A grande tarefa a ser efetivada compreende, entre outros aspectos, a revisão dos serviços de atendimento ao público com vistas a sua maior eficácia e humanização. Isto sugere repensar intensamente os modelos organizacionais em vigor e para isso, um instrumento de grande relevância para auxílio dessa nova administração pública é a gestão do conhecimento.

\section{A Era da Informação e do Conhecimento}

A sociedade moderna tem acompanhado nos últimos anos o desenvolvimento e a ampliação rápida da capacidade de processamento das informações. Essas modificações impactam a sociedade, na economia, na política, nos processos produtivos, nas relações de trabalho, no meio acadêmico, na cultura e na maneira como a administração pública é percebida pela população em geral.

$\mathrm{O}$ atual desenvolvimento das telecomunicações e da informática tem incitado reflexos em todos os tipos de organizações e no modo como são produzidos os bens e serviços. "Isso ocorre na medida em que o mercado passa a ser cada vez mais globalizado, as preferências do consumidor mais exigentes, o ciclo de vida dos produtos mais curto e os limites de tempo e distância inexistentes" (SCHLESINGER, 2008, p. 9).

Sendo assim, inovar torna-se uma ação fundamental no meio organizacional, e para que haja o desenvolvimento de bens e serviços de forma inovada e criativa deve estar imbutida nessas ações a informação e o conhecimento.

Para Schlesinger (2008, p. 9),

A revolução digital, da mesma forma que cria novas oportunidades de inovação e crescimento, gera instabilidades ao provocar fenômenos e mudanças em diversos aspectos da organização social. Entre as oportunidades, podem ser destacadas: a disseminação instantânea de informações, as possibilidades do ensino à distância, o comércio eletrônico, as comunidades virtuais, as novas modalidades de emprego (de especializado para multidisciplinar) e outras, principalmente via Internet. Entre os fenômenos, destacam-se: a "economia digital", a globalização da economia, as crises financeiras interdependentes, o aumento da exclusão dos países em desenvolvimento, a tendência à falta de empregos em setores já estabilizados, a migração de fábricas, a intensiva cobrança de qualidade dos serviços públicos pela sociedade, entre outras. 
A sociedade da informação e do conhecimento no que diz respeito ao mundo laboral, ou seja, relação aos empregos, permite a criação de "postos de trabalho" que exigem maior nível de capacidade, de habilidade de pensar criticamente, de planejar estrategicamente e de ininterrupta adaptação. Até meados da década de 1980, as áreas de informação, informática e telecomunicações estabeleciam-se de maneira estagnada, distinta e independente. Todavia, o desenvolvimento tecnológico, o processo de globalização e o desenvolvimento dos mercados geraram uma convergência de atividades, interesses e potencialidades, ocasionando o que se convencionou denominar de Setor de Informação. Esse campo passou a ser muito valorizado diante da elevada demanda por informação e conhecimento, elementos de vantagem competitiva de empresas, indústrias e países.

Assim, a sociedade da informação é aquela que tem "o acesso democratizado, universal, global e total à informação e ao conhecimento, através dos meios de comunicação e equipamentos eletrônicos (...) ( MUSACCHIO, 2014, p. 1). A perspectiva dessa nova sociedade tem feito com que muitas nações, a exemplo dos EUA, Canadá, Japão, entre outros, como também organismos internacionais, tais como Unesco, G7 e World Bank organizem e implantem programas e iniciativas com o intuito de dominar e/ou democratizar o processo da informação.

Já no Brasil, existe um projeto nacional, coordenado pelo IBICIT - Instituto Brasileiro de Informação em Ciência e Tecnologia, que deu origem ao Programa "Sociedade da Informação", realizado pelo Governo Federal em 2000. Um dos focos deste programa está no e-gov. A sociedade da informação está focada no objeto informação como um produto ou insumo em si, a sociedade do conhecimento deve estar focada na utilização da informação pelo indivíduo como processo. Nesse caso, por conseguinte, a informação estará funcionando como agente mediador da produção do conhecimento (TAKAHASHI, 2000).

A sociedade do conhecimento se produziu a partir das redes sociais, das interações e colaborações, entre pessoas e membros. São individuos debatendo questões, refletindo acerca delas, instruindo e aprendendo, uns com os outros, em todas os campos do conhecimento. Na Era do Conhecimento, os indivíduos desempenham papel fundamental, haja vista que os bens e serviços deixam de ser simplesmente tangíveis passando a ser intangíveis e muito dependentes da ação do ser humano. Isso fica claro quando se analisa um acelerado deslocamento da indústria para os serviços através do conhecimento. Em uma organização contemporânea, o conhecimento deve estar voltado a fazer algo, ou seja, comprometido com uma atividade-fim. Essas empresas têm como principal finalidade tornar os conhecimentos produtivos, alargando assim, a sua capacidade de gerar resultados.

De acordo com Schlesinger (2008, p. 9)

As "organizações do conhecimento" ou "empresas do conhecimento" melhor caracterizadas estão no setor de serviços e vendem conhecimento, informação e outros serviços. Entre elas estão as agências de propaganda, escritórios de 
advocacia, consultorias especializadas e organizações congêneres que têm algumas características em comum: os funcionários são profissionais altamente qualificados e com elevado nível de escolaridade; apresentam poucos ativos tangíveis; utilizamse de grupos locais de clientes e fornecedores para aumentar suas bases de conhecimento.

Vendo por esse prisma, observa-se que as características acima citadas são de grande relevância, por isso, a educação e as relações sociais são cruciais na sociedade da informação e do conhecimento, tendo em vista que os espaços de criação do conhecimento determinam muito mais do que tecnologia, indivíduos em permanente diálogo.

Contudo, a sociedade do conhecimento não é e não será constituida única e tão somente de empresas com as características supracitadas. Muitas irão considerar a informação e o conhecimento com distintos graus de interesse e possibilidades de emprego face às suas particularidades. Haverá organizações atuantes em campos de conhecimento intensivo, de alta tecnologia - mercados de não commodities - e que necessitam de informações e de conhecimentos acerca do seu ambiente interno e externo. Do mesmo modo, a criação do conhecimento no ambiente organizacional dependerá sempre mais de um processo de gestão diferente daqueles usados até o momento.

Em resumo, os negócios atuais precisam inserir em suas atividades o conhecimento, pois, o mesmo se tornou um elemento de sobrevivência das organizações. As principais transformações que ocorreram na sociedade globalizada, inclusive no mercado de negócios nas últimas décadas, têm exigido maior experiência e conhecimento dos envolvidos. Destarte, somente o uso adequado do conhecimento promoverá o desenvolvimento de produtos e serviços com custos mais competitivos e qualidade superior. Na Administração Pública não é diferente, o conhecimento passa também a ser condição sine qua non para que os resultados gerados sejam positivos.

\section{Gestão do Conhecimento: considerações}

De acordo com Dos Reis (2005), a gestão do conhecimento em ambientes corporativos é adotada como instrumento provedor de transformações nos aspectos relacionados à organização e ao comportamento das pessoas que constituem a empresa, mediante o incentivo à necessidade de se atuar em equipe, compartilhando experiências, habilidades e competências no que se refere ao gerenciamento do armazenamento das informações, com o objetivo de se estabelecer o conhecimento como alicerce para as ações destinadas às organizações, garantindo assim a sobrevivência.

Deste modo, Dos Reis (2005), enfatiza que a gestão do conhecimento se apresenta dentro da gestão, como um importante instrumento de estratégia para facilitar a gerência das entradas de informações, com o intuito de formular uma base de conhecimento organizado. Neste sentido, para a autora, as práticas estabelecidas transcrevem a iniciativa de se coordenar meios informativos que 
servirão como bens estratégicos que atribuem para a informação um caráter cujo teor basilar culmina em auxiliar o homem a formar e organizar seu pensamento para tomar decisões.

Para Terra (2001), a gestão do conhecimento é definida, portanto, como um grande e acertado procedimento de definição, ampliação, sistematização de compartilhização do conhecimento de modo bem arquitetado, de grande importância para as organizações; tornando-se, como resume Wiig (2006), um gerenciamento integrado do conhecimento organizacional bem solidificado a partir do uso de tecnologias de informação e comunicação.

As opiniões sobre o gerenciamento do conhecimento divergem quando se trata de definir a temporalidade de sua aplicação; pois, para alguns autores, o mesmo é algo relativamente novo, tendo sua concepção fundamentada na ideia de que o mesmo é dependente da tecnologia de informação e da rede mundial de computadores para a sua execução. Um dos autores que defende essa concepção é Egoshi (2006, p.2) que diz:

A Gestão do Conhecimento da Era Internet é algo novo, revolucionário e sem precedentes na História da Humanidade, porque é sustentada por uma Tecnologia de Informação aliada às melhores Práticas e Teorias de Gestão. Sem esses dois alicerces, não haveria a Gestão do Conhecimento que tanto falam por aí hoje em dia em plena Era Internet. (GRIFOS DO AUTOR).

Para o autor supracitado, a gestão do conhecimento depende, portanto, da sustentabilidade fornecida pela tecnologia da informação, assim como a teoria e prática da gestão que juntos possibilitaram a revolução do gerenciamento do conhecimento, tão em alta no cenário global da era virtual.

Entretanto, para muitos autores como Fleury, Oliveira Junior (2001), Terra (2001) e Zabot e Silva (2002), a concepção existente sobre a gestão do conhecimento é equivocada. Para os mesmos, a gestão do conhecimento não pode ser concebido como algo novo dentro da administração de empresas; e nem tão pouco pode ser encarado como uma tendência do momento, sem ter a real importância merecida. A gestão do conhecimento é compreendida por eles como o resultado de preocupações, de análises e práticas resultantes da aprendizagem organizacional que recebeu importante influência das gestões tecnologógica e cognição empresarial.

Para os autores Nonaka e Takeuchi (1997), o conhecimento se origina tanto das experiências de vida, assim como dos valores, crédulos, das tradições transmitidas pelas gerações, como dos hieróglifos, das normatizações estabelecidas, assim como das políticas e manual, dando origem a duas fontes diferentes de conhecimento: tácita e explícita.

Esses distintos modos de conhecimento se organizam portanto, como as informações processadas pelo cérebro do homem, originando o conhecimento intrínseco, interno, que se caracteriza 
pela dificuldade de ser originado e consequentemente comunicado; já o explícito, resultado do conhecimento que é trasmitido a partir de uma linguagem estrutural e sistematizada.

Diante desse contexto, Dos Reis (2005), explica que neste sentido, o gerenciamento do conhecimento passa a ser uma fonte estratégica a serviço da gestão das informações que entram, surgem. O exercício deste acaba por resultar no gerenciamento das informações para posterior uso estratégico, atribuindo à informação a capacidade de ajudar o homem na execução e formulação do pensamento, assim como organizá-lo.

Para a autora, o ser humano é o centro, sendo ele o agente propulsor do conhecimento; pois, é o homem que cria e caracteriza as diferentes formas do conhecimento, adequando-o com a sua realidade, atribuindo-lhe qualquer nível organizacional ou personalidade. Em contrapartida, no mesmo bloco, encontra-se a tecnologia, que contribui estabelecendo um ritmo intenso ao modo formal e social em que esse conhecimento se estabelece dentro das organizações.

Sobre organizações, Porter (1998), destaca que a gestão do conhecimento refere-se também a competência estabelecida no cenário das organizações com o objetivo de fornecer elementos e conhecimentos, cuja finalidade é a sustentação dos processos decisivos dentro das organizações.

Reis (2005), comenta que um dos grandes desafios para as empresas na atualidade diz respeito ao compartilhamento do conhecimento, que é a base da gestão do conhecimento em parceria com a tecnologia, métodos e práticas que possibilitam a repartição do conhecimento intrínseco e extrínseco com o intuito de formular e organizar o conhecimento para a sua execução, possibilitando a oportunidade de inovar as organizações.

De acordo com Choo (2003 apud de SOUZA, 2006, p.6), o caminho para as empresas desenvolverem o compartilhamento do conhecimento é através do desenvolvimento do potencial humano, de tal modo que:

É necessário, deste modo, que as organizações criem condições que permitam desenvolver o potencial humano de uma empresa de forma dinâmica, desenvolvendo o capital intelectual, as competências individuais e assim proporcionar a configuração de valores coletivistas que incentivem mudanças de atitudes no sentido do desenvolvimento de recursos humanos com maior grau de responsabilização, orientados para o conhecimento.

Para o autor, a organização e o investimento no potencial humano coletivo, contribui para a formulação e valorização do desenvolvimento dos recursos coletivos que irão contribuir para a orientação do conhecimento.

Além da superação deste desafio, outros despontam como importantes para serem superados. De acordo com Santos (2004), alguns desafios são importantes para serem resolvidos pelas empresas como: estabelecer o desenvolvimento das competências humanas internas, o gerenciamento do quadro 
efetivo, a criação de comunidades virtuais e o gerenciamento correto, assim como o estímulo adequado das pessoas.

Para Nonaka e Takeuchi (1997), outros elementos de fundamental preocupação às empresas no que diz respeito ao compartilhamento de informações, está relacionado à formulação de um ambiente que proporcione a criatividade, com a promoção de momentos para que possa haver a troca de conhecimento intrínseco ou extrínseco de modo dinâmico, articulado, com objetivo, organizado, intuitivo, em uma estrutura espiralizada que possibilita movimentos amplos e ilimitados.

Contudo, Tonet e Torres da Paz (2006, p. 76) informam que:

No atual cenário das organizações, o compartilhamento de conhecimento tem mostrado ser de suma importância, mas de difícil concretização, embora o senso comum identifique facilmente o que é compartilhar conhecimento, ainda não há consenso empírico sobre o significado do construto.

Apesar do entendimento da necessidade do compartilhamento do conhecimento, a sua realização por parte das empresas mostra-se um grande desafio para as mesmas, em decorrência da ausência de uma formação emprírica consensual que fortaleça o entendimento deste instrumento para sua real concretização por parte das empresas.

Neste contexto, portanto, Santiago Júnior (2004, p. 22), faz um importante alerta às empresas, dizendo-lhes que:

\begin{abstract}
As empresas devem entender que o conhecimento se tornou um ativo mais importante, e indispensável, por ser a principal matéria-prima com a qual todas trabalham. A partir deste entendimento, é possível observar o quanto ele é mais valioso e poderoso que qualquer outro ativo físico ou financeiro. Além disso, deve-se observar que, muitas vezes, a maior parte dos conhecimentos que uma organização necessita para se manter competitiva, ela já possui, no entanto está, por vários motivos, inacessível. A criação de um ambiente propício para identificar, criar e disseminar o conhecimento irá agregar valor à empresa e a colocará no rumo de atingir suas metas.
\end{abstract}

Ou seja, para o autor supracitado, o maior benefício para o desenvolvimento de sua empresa está no compartilhamento do conhecimento; pois, é a partir do desenvolvimento de estratégias para o aprimoramento destas, que outras ações pertinentes poderão ser colocadas em prática para favorecer o desenvolvimento da empresa, podendo assim, usufruir de forma eficiente dos elementos intrínsecos e extrínsecos que a mesma possui, potencializando seus reais efeitos em benefício próprio. 


\section{A Gestão do Conhecimento como instrumento para obtenção de melhores resultados nos serviços da administração pública}

Nos dias atuais, grandes estatais brasileiras são consideradas, como referências em gestão do conhecimento. Não por acidente, grande parte dessas empresas faz parte da Sociedade Brasileira de Gestão do Conhecimento (SBGC). Como é de conhecimento público, essas organizações captam fatia maior do Produto Interno Bruto nacional (PIB). São as que mais geram riquezas ao Brasil e as que possuem melhor visibilidade pela economia internacional. Isto quer dizer que, mesmo sendo rudimentar na administração direta, a Gestão do Conhecimento está cada dia mais presente nos planos estratégicos governamentais. Um estudo realizado pelo IPEA (Instituto de Pesquisa Econômica Aplicada) demonstra que quando as práticas deste tipo de gestão são bem aplicadas pelo poder público, não só desempenham a finalidade de melhorar, o desempenho da organização, mas também transformam o conhecimento em ferramenta catalisadora de inovação e produtividade (MATOS, 2011)

O recurso também permite que indivíduos em determinados cargos estratégicos ou operacionais deixem de ser rotulados como insubstituíveis, ou, quando substituídos, seja minimizada a perda do conhecimento por eles motivado e ou gerenciado, já que a Gestão do Conhecimento estabelece os saberes da instituição, com o objetivo de reproduzir e gerar novas competências. Com o conhecimento tácito registrado e difundido, é possível habilitar outros profissionais para a efetivação das mesmas atividades e, inclusive, aperfeiçoar os processos, já que todos podem contribuir com o conhecimento organizacional (MATOS, 2011).

O reconhecimento do essencial papel da Gestão do Conhecimento na prática da administração pública é bastante recente. E devido o atual cenário em que está inserida a gestão pública, a mesma não pode desconhecer as mudanças que vêm transformando as organizações públicas e privadas no panorama nacional e internacional. Diariamente aparecem novas oportunidades desafiadoras que apontam rupturas na dinâmica das estruturas tradicionais, e que estão inteiramente relacionadas ao desenvolvimento tecnológico e ao processo de globalização.

De acordo com Runte (2011, p. 26):

É importante que a administração pública desenvolva sua própria capacidade de trabalhar a Gestão do Conhecimento, não de forma a se tomar uma cópia do setor privado, mas criando o seu movimento estratégico, esforçando-se por inovar em conformidade com a sua própria identidade e especificidade em trabalhar o conhecimento.

Karl Wiing (2000 apud RUNTE, 2011), ressalta a relevância e complexidade da Administração Pública em qualquer sociedade, já que é através desta que a sua cultura é determinada, 
assim como a qualidade de vida. E ainda, uma atuação ineficaz da administração pública poderá induzir a sociedade ao declínio. o autor assegura que o amplo campo da Gestão do Conhecimento introduz novas alternativas, capacidades e práticas que auxiliam a administração pública a se modificar e adquirir novas responsabilidades em gerir o conhecimento de modo a obter efetividade e melhoria à sociedade na qual pertence e serve.

Para isso, diferentes são os aspectos referentes à Gestão do Conhecimento: papel da alta gestão, cultura e estrutura organizacionais, práticas de gestão de recursos humanos, impacto dos sistemas de informação e mensuração de resultados, alianças estratégicas, entre outros. Este enfoque mostra o entendimento de que a Gestão do Conhecimento reflete na coordenação sistêmica de esforços em múltiplos campos: organizacional e individual; estratégico e operacional; normas formais e informais (SOUZA et al. s.a). Ou seja, a Gestão do Conhecimento na Administração Pública é um instrumento que promove uma maior qualidade no andamento de todos as áreas e serviços e, consequentemente, pode auxiliar para alcance de bons resultados.

É válido destacar que um serviço público de qualidade é aquele que é apropriado às necessidades da população; que realiza com excelência a oferta de serviços e no atendimento de modo geral. A sociedade exige que melhores práticas de atendimento sejam efetivadas na Administração Pública. Pois, é por meio da qualidade que as necessidades explícitas e implícitas dos cidadãos são satisfeitas. (INSTRUMENTO PARA AVALIAÇÃO DA GESTÃO PÚBLICA, 2007).

Além da qualidade, a eficiência e o princípio da efetividade social são importantes para a Administração Pública, pois esta precisa prestar contas dos resultados sociais e econômicos das políticas públicas. A efetividade social refere-se aos resultados; objetivos práticos a serem atingidos, ao público-alvo, ou seja, os setores sociais beneficiados e aos macroindicadores para monitorar os resultados das políticas públicas. Tem efetividade social também quando existe intercâmbio entre uma política pública com outras políticas que visam atender ao mesmo conjunto de cidadãos usuários ou com objetivos macrossociais convergentes (INSTRUMENTO PARA AVALIAÇÃO DA GESTÃO PÚBLICA, 2007; BATISTA, 2012).

Os princípios constitucionais da legalidade, impessoalidade, moralidade, publicidade e eficiência dos órgãos e entidades da Administração Pública são também resultados esperados pelos cidadãos. Não basta que o serviço público prestado por uma organização tenha qualidade. É condição sine qua non que seja respeitado o quesito da legalidade, ou seja, que haja uma rigorosa obediência à lei. Não há resultado bom ou gestão excelente à revelia da lei (INSTRUMENTO PARA AVALIAÇÃO DA GESTÃO PÚBLICA, 2007; BATISTA, 2012).

Ressalta-se que os serviços prestados pela Administração Pública devem ser conduzidos de forma impessoal, isto é, fazer acepção de pessoas não é permitido. Os predicados de qualidade do serviço público (cortesia, rapidez no atendimento, a confiabilidade e o conforto) precisam ser prestados a todos os cidadãos de modo indistinto. $\mathrm{O}$ tratamento diferenciado só é permitido nos casos 
previstos em lei. Sendo assim, para que haja qualidade, eficiência e também para que os princípios da efetividade social sejam realizados é fundamental que as entidades públicas utilizem em sua administração a prática da Gestão do Conhecimento.

Neste setor, uma ativa Gestão do Conhecimento auxilia as organizações a encarar novos desafios, implementar práticas inovadoras de gestão e melhorar a qualidade dos processos, produtos e serviços públicos em prol do usuário dos mesmos, como também de toda a sociedade.

É válido salientar que para a Gestão do Conhecimento ser efetivada, o servidor público deve participar das iniciativas, necessita ampliar seus conhecimentos e aptidões. Pois, através dos processos de Gestão do Conhecimento, o servidor público pode adotar posturas positivas em relação à aprendizagem e seguir importantes valores éticos e morais.

Em geral, a Gestão do Conhecimento é um instrumento que aumenta a capacidade da Administração Pública que pode culminar no alcance da excelência dos serviços e, por conseguinte, dos resultados através do melhoramento dos processos internos, desenvolvimento de competências eficazes e planejamento de estratégias inovadoras que refletirão no atendimento ao cidadão-usuário.

\section{Considerações Finais}

A partir da realização deste ensaio teórico a respeito da gestão do conhecimento e sua contribuição para a geração de resultados positivos na esfera da administração pública, de modo a trazer benefícios à população, conclui-se que a gestão de conhecimento é de suma importância para o desenvolvimento de qualquer empresa, e no que se refere ao nosso objeto de estudo - a administração pública - sua importância se potencializa em decorrência da abrangência que tais instituições possuem para o desenvolvimento de um país; sendo muitas vezes, como acontece com o Brasil, importante fonte de desenvolvimento interno.

Considerando-se o potencial da cultura global em que vivemos, onde a informação e o conhecimento configuram-se como importantes ferramentas para o desenvolvimento, na esfera da gestão empresarial, seja ela pública ou privada, o conhecimento não pode passar despercebido, configurando-se como o principal capital "físico" e intelectual da empresa. De tal modo, que investir na gestão do conhecimento torna-se imperioso em qualquer situação, especialmente por promover diversas alternativas que podem auxiliar a administração pública para promover as melhorias essenciais e necessárias para que seja possível trazer à luz o desenvolvimento social.

Neste sentido, a gestão do conhecimento enriquece a capacidade da administração pública. Todavia, para que tal intento possa ser alcançado, ações precisam ser feitas, onde se deve investir no desenvolvimento e no compartilhamento do conhecimento, seja ele intrínseco ou extrínseco, de modo que tal ação torne esse conhecimento fluido, dinâmico e em movimento. 
É importante, portanto, que o servidor público se comprometa em ampliar e compartilhar o conhecimento obtido, desenvolvendo e contribuindo para a aquisição de novas aptidões, em ações conjuntas que visam o ato de aprender, ensinar e compartilhar, sempre abrangidos por valores éticos e morais que em conjunto resultarão em benefícios revertidos e voltados para o desenvolvimento de estratégias direcionadas ao cidadão.

\section{Referências}

BATISTA, F. F. Modelo de gestão do conhecimento para a administração pública brasileira: como implementar a gestão do conhecimento para produzir resultados em benefício do cidadão. Brasília: Ipea, 2012.

DAFT, R.L. Administração. São Paulo: Cencage Learning, 2010, p. 687-700

DRUCKER, P. O Melhor de Peter Drucker: o homem. São Paulo: Nobel 2001.

EGOSHI, K. Gestão do Conhecimento da Era Internet. 2006. Artigo em Hypertexto. Disponível em: . Acesso em: 15 out. 2006.

FLEURY, M. T. L.; OLIVEIRA JUNIOR, M. M. Gestão estratégica do Conhecimento: integrando aprendizagem, conhecimento e competências. São Paulo: Atlas, 2001.

INSTRUMENTO PARA AVALIAÇÃO DA GESTÃO PÚBLICA. Ciclo, 2007.

Disponível em: <http://ww2.prefeitura.sp.gov.br/arquivos/secretarias/subprefeituras/

pqgp/materiais_consulta/0001/Instrumento_Avaliacao_GESPUBLICA.pdf >

Acessado em: 10 dez. 2007.

MATOS, U. Gestão do Conhecimento na Gestão Pública, 2011. Disponível em: http://sbgc.org.br/sbgceduc/?p=543. Acesso em: 24 mar. 2016.

MELO, W. F.de; SANTOS, C.M.B. dos; SCHMIDT FILHO, R.; MENDES, F.A; MONTEIRO, A. Conceitos, funções e princípios da Administração Pública e suas relações com a Lei de Responsabilidade Fiscal. In: Âmbito Jurídico, Rio Grande, XVI, n. 116, set 2013. Disponível em: <http://www.ambito-juridico.com.br/site/?n_link=revista_artigos_leitura\&artigo_id=13653>. Acesso em mar 2016.

MUSACCHIO, C. Sociedade da Informação x Sociedade do Conhecimento. 2014. Disponível em: http://www.baguete.com.br/colunas/claudio-de-musacchio/26/07/2014/sociedade-da-informacao-Xsociedade-do-conhecimento. Acesso em: 30 mar. 2016.

NONAKA, I.;TAKEUCHI, H. Criação de conhecimento na empresa. Rio de Janeiro : Campus, 1996.

REIS, M.E.A.dos. Portal corporativo como ferramenta de gestão do conhecimento na administração pública. Dissertação (mestrado) - Escola Nacional de Saúde Pública Sérgio Arouca, p.129, 2005. 
REIS, V.G.dos. Gestão do conhecimento e cultura organizacional: um estudo de caso na FiocruzBahia/ Valdeyer Galvão dos Reis. Recife: V. G. dos Reis, 2007.

RUNTE, G.I.B.da C. Gestão do Conhecimento os desafios da implantação de um modelo integrado o caso ANS. 143 f. Dissertação. Fundaçáo Getúlio Vargas, Rio de Janeiro, 2011. Disponível em:

http://bibliotecadigital.fgv.br/dspace/bitstream/handle/10438/9063/1422899.pdf?sequence=1. Acesso em: 29 mar. 2016.

SANTIAGO JÚNIOR, J.R.S. Gestão do conhecimento: a chave para o sucesso empresarial. São Paulo: Inovatec, 2004.

SANTOS, M. J. N. Gestão de recursos humanos: teorias e práticas. Sociologias, Porto Alegre, ano 6, n. 12, p. 142-158, jul/dez. 2004.

SCHLESINGER, C.C.B. Gestão do Conhecimento na Administração. Curitiba: Instituto Municipal de Administração Pública - IMAP, 2008 120p.:

SOUZA, D. B.L.de. Gestão do conhecimento nas organizações: desafios e oportunidades. Estação Científica, Juiz de Fora, n. 03, p. 14, out. 2006.

SOUZA, A.M.de. et al. A Gestão de Pessoas alinhada à Gestão do Conhecimento. 2015.

Disponível em: http://www1.serpro.gov.br/publicacoes/gco site/m capitulo04.htm. Acesso em: 28 mar. 2016.

TAKAHASHI, T. Sociedade da informação no Brasil. Brasília : Ministério da Ciência e Tecnologia, 2000. xxv, 195p.

TERRA, J.C.C. Gestão do Conhecimento: o grande desafio empresarial. São Paulo: Negócio Editora; 2001.

TISCOSKI, R.B. Perspectivas e Tendências Sobre a Participação do Cidadão na Administração Pública. 2013. 52 páginas. Monografia do Curso de Administração - Linha de formação Específica em Administração de Empresas, da Universidade do Extremo Sul Catarinense - UNESC.

TONET, H. C.; TORRES DA PAZ, M. G. Um modelo para compartilhamento de conhecimento no trabalho. Revista de Administração Contemporânea, v. 10, n.2, p. 75-94, abr/jun. 2006.

WIIG, K. Entrevista. Revista GC Brasil, n. 1, p. 05-09, ago. 2006.

ZABOT, J. M., SILVA, L. C. M. Gestão do Conhecimento: aprendizagem e tecnologia: construindo a inteligência coletiva. São Paulo: Editora Atlas, 2002.

\section{Como citar este artigo (Formato ABNT):}

BEZERRA, Flávia S.; SOUZA, Ricardo dos S.; CASSUNDÉ, Fernanda R. de S. A . Uma Discussão Teórica sobre a Importância da Gestão do Conhecimento na Administração Pública. Id on Line Revista de Psicologia, Fevereiro de 2016, vol.10, n.29, p. 129-143. ISSN 1981-1179.

Recebido: $14 / 02 / 2016$

Aceito: $25 / 02 / 2016$ 